This item was submitted to Loughborough's Research Repository by the author.

Items in Figshare are protected by copyright, with all rights reserved, unless otherwise indicated.

\title{
A cost effective far side crash simulation
}

PLEASE CITE THE PUBLISHED VERSION

LICENCE

CC BY-NC-ND 4.0

\section{REPOSITORY RECORD}

Bostrom, Ola, Robert Judd, Brian Fildes, Andrew Morris, Laurie Sparke, and Stu Smith. 2019. "A Cost Effective Far Side Crash Simulation". figshare. https://hdl.handle.net/2134/2171. 
This item was submitted to Loughborough's Institutional Repository (https://dspace.lboro.ac.uk/) by the author and is made available under the following Creative Commons Licence conditions.

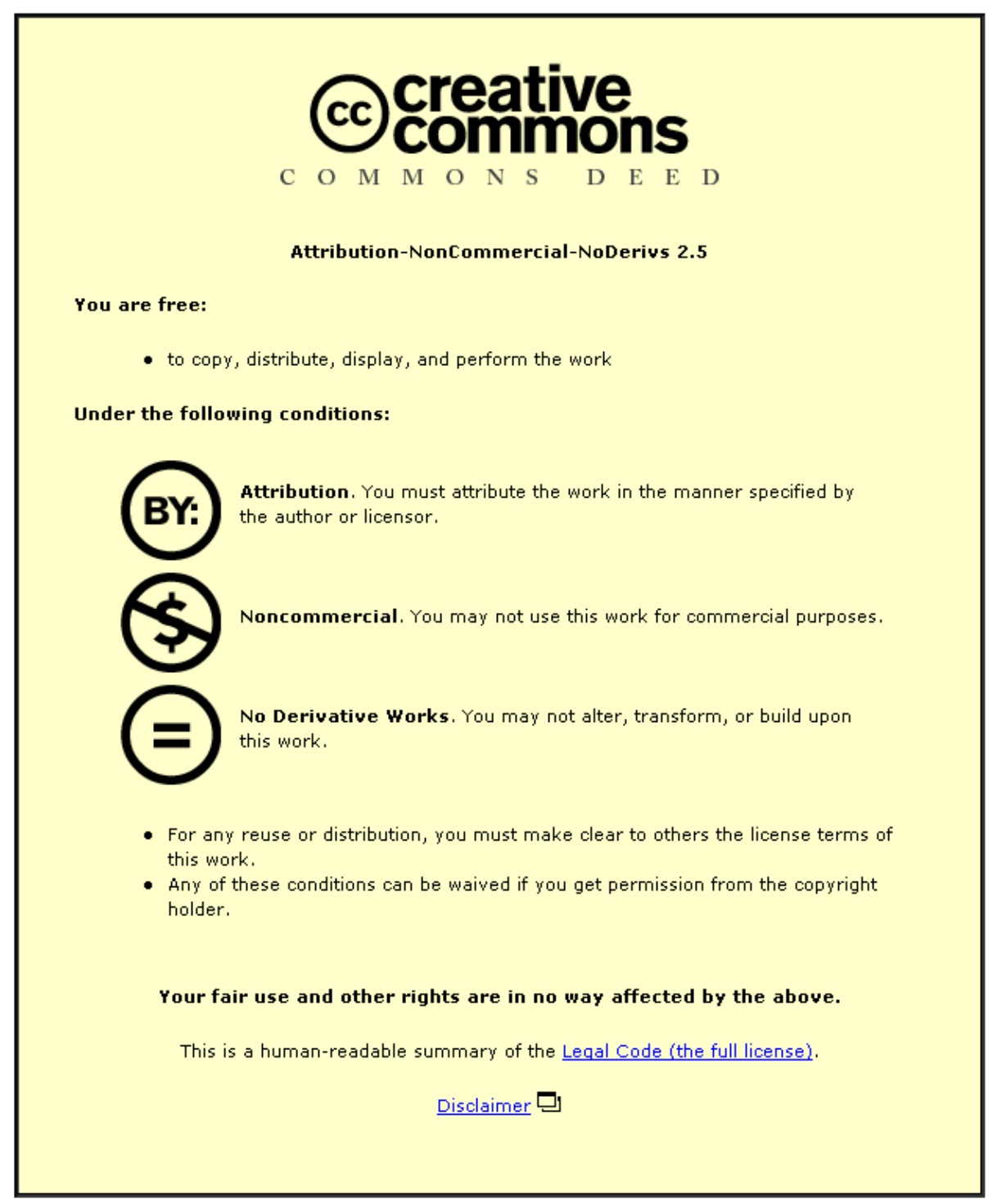

For the full text of this licence, please go to: http://creativecommons.org/licenses/by-nc-nd/2.5/ 


\title{
A cost effective far side crash simulation
}

\author{
Ola Bostrom*, Robert Judd**, Brian Fildes*** \\ Andrew Morris***, Laurie Sparke****, Stu Smith**** \\ *Autoliv Research, 44783 Vargarda, Sweden \\ **Autoliv Australia, Campbellfield, Vic. 3061, Australia \\ ***Monash University Accident Research Centre, Clayton, Vic. 3800, Australia \\ ****Holden Ltd, Port Melbourne,Vic. 3207, Australia
}

\begin{abstract}
According to real-life crash data, one of the most harmful events among all side impacts is when the driverhead hits the far-side door when the car is hit from the far side. There is currently no established test method to simulate a crash where such an event is at risk of occurring. In order to assess real life injuries and develop countermeasures for far side crashes, standardized cost-effective test methods are needed.

This paper presents a bending bar sled-test set-up simulating a full-scale 3 o'clock far side crash. In the full scale crash-test a deformable barrier with a speed of $65 \mathrm{~km} / \mathrm{h}$ struck the passenger side of a passenger car with a BioSID in the driver seat. The intrusion of the vehicle was over when the dummy hit the far side door and therefore there was no requirement to simulate intrusion rate and extent in the sled test. The remaining part of the deformed vehicle was chopped in front of the instrument panel and behind the front seats and was then fastened transversely onto a sled. The intruded passenger side was fixed and reinforced. The mid-console, the passenger door-trim and the belt system were replaced. A BioSID was placed in the driver seat according to the full scale crash and the sled impacted the chosen set of iron bars with a resulting $\Delta \mathrm{v}$ of $24 \mathrm{~km} / \mathrm{h}$. As a result, the kinematics, accelerations and loading of the dummy were essentially the same as in the corresponding full scale crash. In conclusion, a sled test set-up can be used to assess real life injuries and in the development of dummies and countermeasures for far side crashes of similar types as considered in the paper.
\end{abstract}

\section{INTRODUCTION}

A vehicle occupant can be directly adjacent to, or on the far side of the struck side of the vehicle in the event of a side impact crash. According to Australian real-world crash data [1], the second most harmful event among all side impact crashes (near and far side) is when the driver's head hits the far-side door where Harm is defined as the metric combination of injury frequency and injury costs. The risk of a severe head injury is twice as high when the vehicle is hit from the far side compared to the near side since in the near-side event, there is a high probability that the head will exit through the door window aperture and not strike anything. Facts from real-life crashes found in other regions of the world, US [2], UK [3,4,5] and Germany [6], support the Australian findings.

Test methods have been developed for near side crashes and these are used in both legislation and consumer tests. Side airbags for the thorax and the head are becoming standard equipment and are predicted to significantly reduce the risk of injury for near side occupants in side impacts, although there are no field data as yet. However, there are no established far-side crash-testmethods and dummies, legislation nor consumer assessments. Furthermore, in the consumer and legal near side crash tests, the additional loading of the near side occupant incurred by the far side occupant is not taken into account. Due to the high cost ratio between a full scale and a simple sled test (at least 5 to 1, not taking into account the cost of the car in the full-scale test), a sled test method is preferred in the development process of far side dummies and far side countermeasures.

Few tests involving far side occupants in full scale and sled side impact tests have been reported in the literature. In order to understand the occupant kinematics that causes the most frequent injuries, Digges and Dalmotas [2] performed full-scale side-impact crashes with three different 
belt systems. A 1998 Chevrolet pickup with a $50 \%$ HIII on the far side was impacted by a 50 $\mathrm{km} / \mathrm{h}$ speeding full size passenger car 60 degrees relative to the centre line. For all three beltsystems the dummy slipped out of the sash belt but the injury readings were low, leading the authors to the conclusion the test configuration was not representative of the crashes that produce severe injuries in the real world. Although the three point belt offers poor protection $[2,4]$, Stoliski et al [7] showed by means of far side HIII and US-SID full-scale crashes, deploying belt pre-tensioners can significantly reduce lateral excursion of the far side occupant and reduce lap belt loads. Kallieris and Schmidt [8] conducted a series of full scale crashes with an impacting speed of $50 \mathrm{~km} / \mathrm{h}$ using a direction of force of both 60 and 90 degrees between the striking vehicle and the centre line of the struck car. The test objects used were US-SIDS and cadavers seated on the far side in the rear seat restrained by a reversed belt system. The authors concluded that the reversed three-point belt system prevented large lateral displacement of the upper part of the body. However, most of the cadavers showed AIS1 injuries to the neck, which in the light of recent whiplash research corresponds to a high probability of disabling injury outcome (i.e. hemorrhages in the inter-vertebral discs). Clearly, there is a need for further research in this area but first, a suitable test method is required for reducing injuries to occupants in far-side crashes.

A far side test configuration which is representative of crashes that produces severe injury in the real world should obviously reflect the high risk of severe head injuries, abdominal loading and any other injurious events. The aim of the present paper was to develop a cost-effective sled test method to be used to develop a far side dummy, which could be used to assess real life injuries and develop countermeasures. Far side impacts include oblique and perpendicular crashes with different degrees of intrusion. The focus in this study was set on perpendicular crashes with between 100 and $500 \mathrm{~mm}$ of intrusion, which is a condition whereby belted far side occupants would benefit most from an improved restraint system [4].

\section{METHOD}

In this section two tests are described. First, the full-scale baseline-test and thereafter the bending bar sled test designed to replicate the full-scale test. As the results of the full-scale tests were used in the sled test, they are partly presented in this section, while the results of the sled test validation are presented in the Results section. All coordinate systems and filter classes used were in accordance with SAE J211 standard. As the vehicle used was right hand drive and the impact came from the left, the $\mathrm{y}$ and $\mathrm{z}$ dummy accelerations were expected to be positive most of the time.

\section{The Full Scale Test}

The full-scale test was essentially an ADR72/ECE-R95 side impact test with three exceptions. First, the mobile barrier struck the far side of the vehicle with respect to the dummy. Secondly, the dummy was a BioSID instead of EuroSID, and third, the test speed was $65 \mathrm{~km} / \mathrm{h}$. The dummy choice motivation was due to the fact that the BioSID could be equipped easily with lower and upper neck load cells, a requirement in future tests. The details of the test were as follows,

Striking vehicle: Mobile Deformable Barrier (MDB) as per ADR72/ECE-R95 striking the target vehicle perpendicular on the left hand side, at a speed of $65 \mathrm{~km} / \mathrm{h}$. The MDB weight was $990 \mathrm{~kg}$ and the ground height was $290 \mathrm{~mm}$.

Struck vehicle: Holden VT Commodore (manufactured in 1999), right hand drive. The total weight of the car was approximately $1700 \mathrm{~kg}$. The passenger seat was reclined rearwards so that 
it did not come into contact with the dummy positioned in the driver seat during the crash. The driver seat was in the mid-mid (longitudinal-vertical) position. Accelerometers were placed at the non-struck side B-pillar and the longitudinal tunnel in the centre of the car.

Dummy: The BioSID dummy was set up for a left-hand side impact, in the driver position restrained with a three-point belt (without pre-tensioner). The dummy was positioned according to the ADR72/ECE-R95 procedure and the position was recorded with FARO measurement. The head was painted in order to indicate the location of an impact.

Film: Out-board and in-board high-speed cameras were installed (with special support) to document views from the side, rear, front and top of the dummy during the impact.

The struck side intrusion was over at about $70 \mathrm{~ms}$ after the crash started. The dummy torso slipped out from the sash part of the belt, the pelvis hit the mid-console at $30 \mathrm{~ms}$, and the dummy torso rotated and was restrained in z-direction by the lap part of the belt. $150 \mathrm{~ms}$ after the crash started, the head swiped the intruded side at the location of the doorknob on the door just close to the B-pillar. The timing of the head swipe was well after the side intrusion was over. The midconsole pelvis interaction seemed to overlap somewhat with the deformation of the longitudinal tunnel where the mid-console was fastened. The final maximum residual intrusion was measured to be in the order of $300 \mathrm{~mm}$ (at the B-pillar) although during the crash, the dynamic intrusion may have been beyond this level.

Whereas there was no deformation of the non-struck side B-pillar, the acceleration in the ydirection (along the direction of impact) at the driver's side B-pillar and at the tunnel differed significantly. Figure 1 shows the difference in speed time-history. The striking and struck vehicle moved together without separating from each other during the crash and the speed change until the dummy head swiped the door was about $24 \mathrm{~km} / \mathrm{h}$.

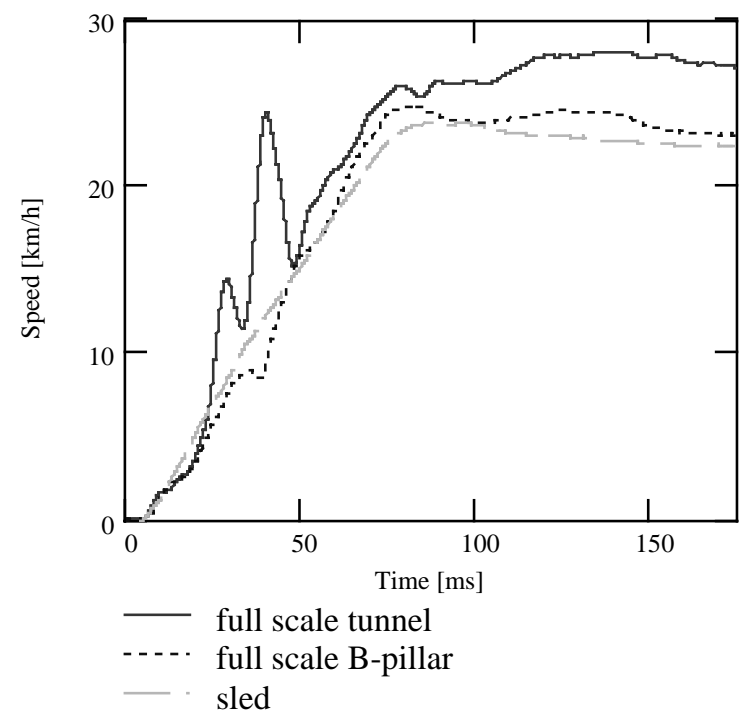

Figure 1 - Struck full-scale car y-speed time history at the driver side B-pillar and at the longitudinal tunnel at the centre of the car. The corresponding sled speed is also indicated. 


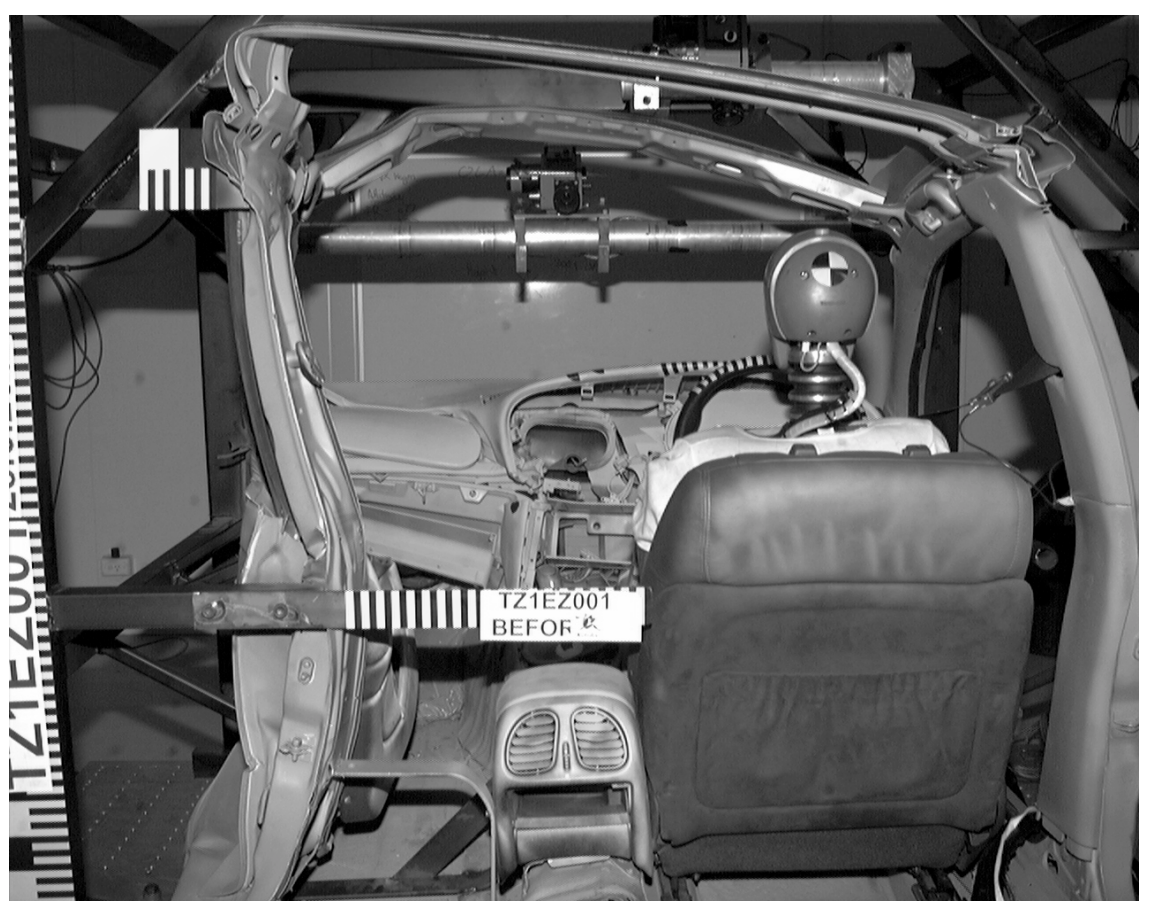

Figure 2 - Pre crash photo, from behind, of the prepared buck fastened transverse on the sled.

\section{The Sled Test}

The deformed car from the full-scale test was chopped in front of the dashboard and behind the front seats (see Figure 2). The remaining buck was reinforced and secured transversally on a sled. The passenger seat was taken away and replaced by a steel support in order to give similar support to the mid-console. The passenger inner door-trim, the mid-console and the driver belt system, the only parts of the test set-up able to deform, were replaced with new parts. The iron bars used in the braking system were chosen to give a constant $10 \mathrm{~g}$ crash pulse. The motivation for the constant pulse was both the repeatability and the prediction that the dynamic distortion of the B-pillar and the tunnel during the full-scale impact would not influence the kinematics of the dummy. A BioSID, instrumented for a left-hand-side impact was positioned identically according to the full-scale test with the use of FARO equipment. The impact speed was chosen to be 22.1 $\mathrm{km} / \mathrm{h}$ in order to get a final $24 \mathrm{~km} / \mathrm{h}$ speed change taking into account the rebound velocity, (see Figure 1). Similar film camera positions used in the full-scale crash were again used in the sled test.

\section{RESULTS}

The dummy y-acceleration of the pelvis, T1 and head are shown in Figure 3-5. The dummy head z-acceleration is shown in Figure 6. All head accelerations were filtered with a CFC1000 filter while for the pelvis and T1, the used filter class was CFC180. The sled-test BioSID moved similarly to that observed in the full-scale test. The torso slipped out of the sash belt and the pelvis again hit the tunnel. The dummy started to rotate because of the tunnel-pelvis impact. The rotation occurred with minor flexibility and was held back by the lap belt. The applied lap belt torque decelerated the dummy rotation effectively because the dummy was laterally stiff and did not bend. In a nearly horizontal position and with resultant head speed of less than $2 \mathrm{~m} / \mathrm{s}$, the head swiped the same spot as in the full scale at almost the same time, (see the head y-acceleration in Figure 5 and the post crash photo in Figure 7). 


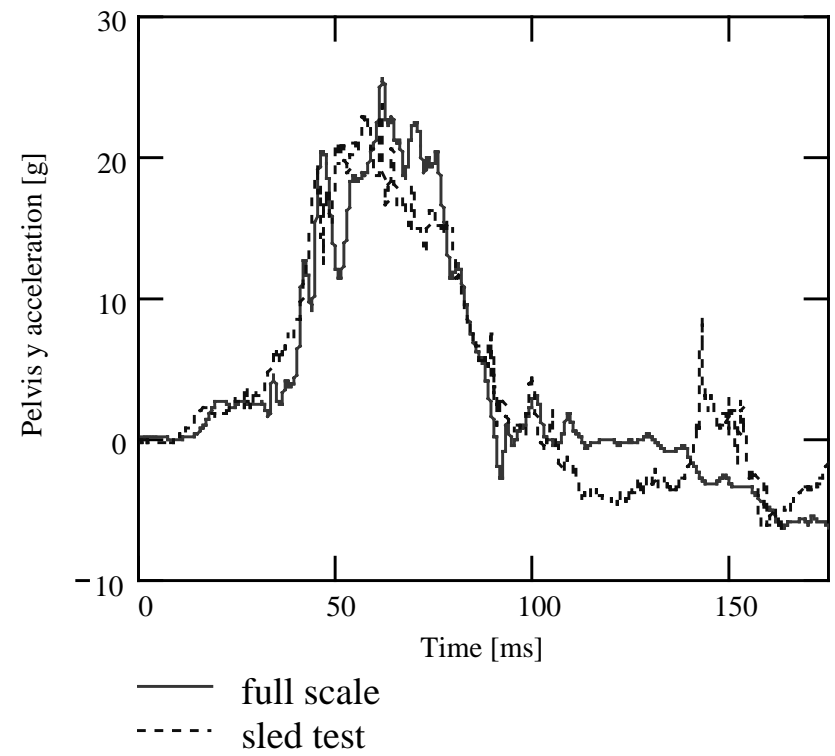

Figure 3 -Pelvis y-acceleration time history for the full scale and the sled test. The negative values after $100 \mathrm{~ms}$ are consequences of the pelvis rebound.

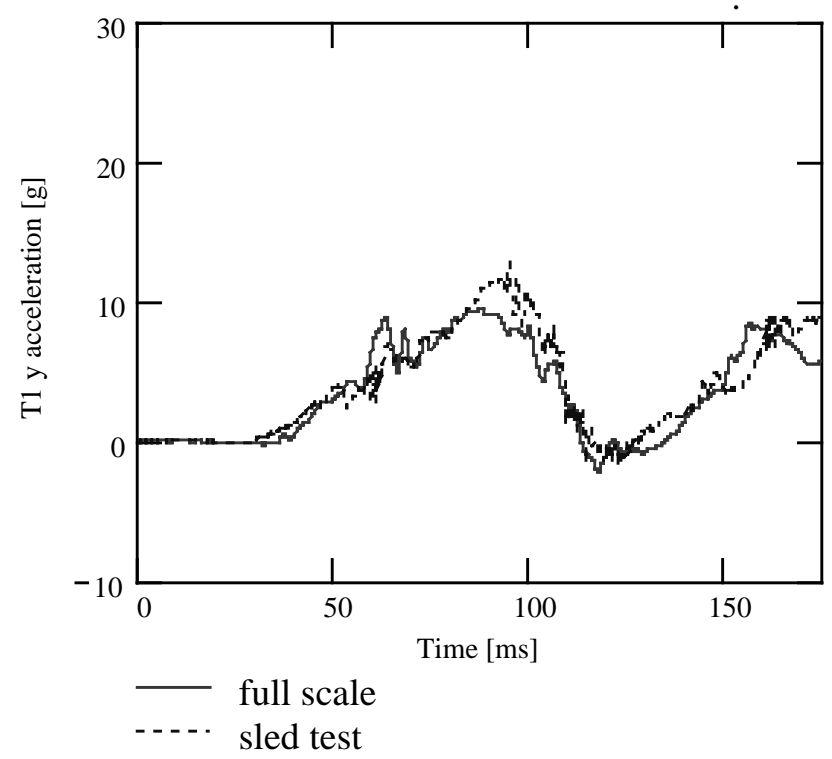

Figure 4-T1 y-acceleration time history for the full scale and the sled test. 


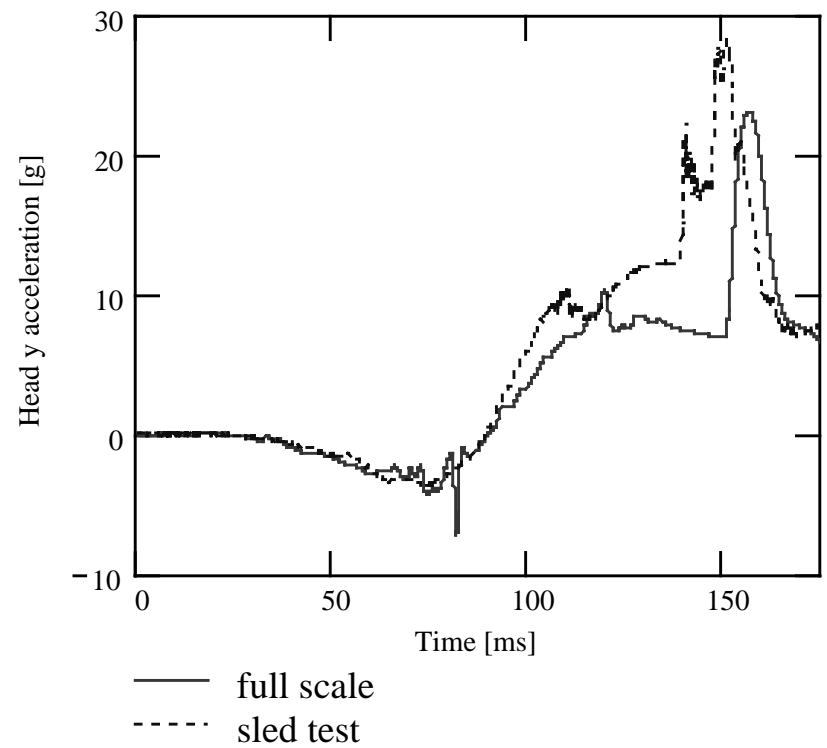

Figure 5 - Head y-acceleration time history for the full scale and the sled test. The initial negative acceleration was due to the rotation of the dummy caused by the pelvis-tunnel impact. The peaks around $150 \mathrm{~ms}$ were a result of the head-door swipe while the major part of the acceleration between $100 \mathrm{~ms}$ and the peak was due to the hold back effect of the lap belt.

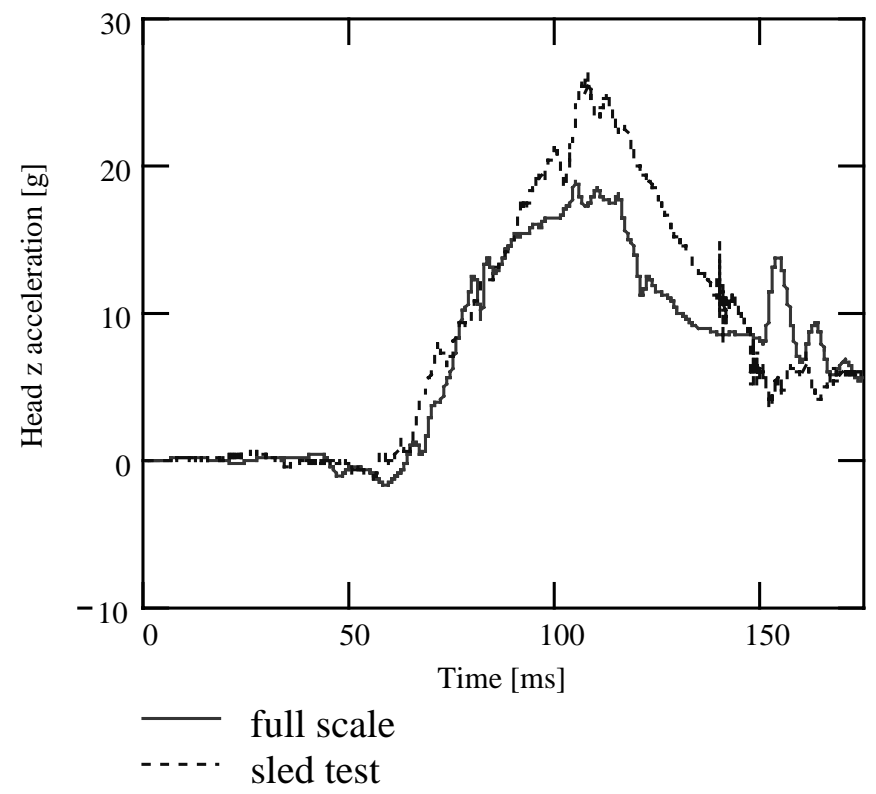

Figure 6 - Head z-acceleration time history for the full scale and the sled test. The positive acceleration was due to the lap belt hindering the dummy pelvis from leaving the seat. 


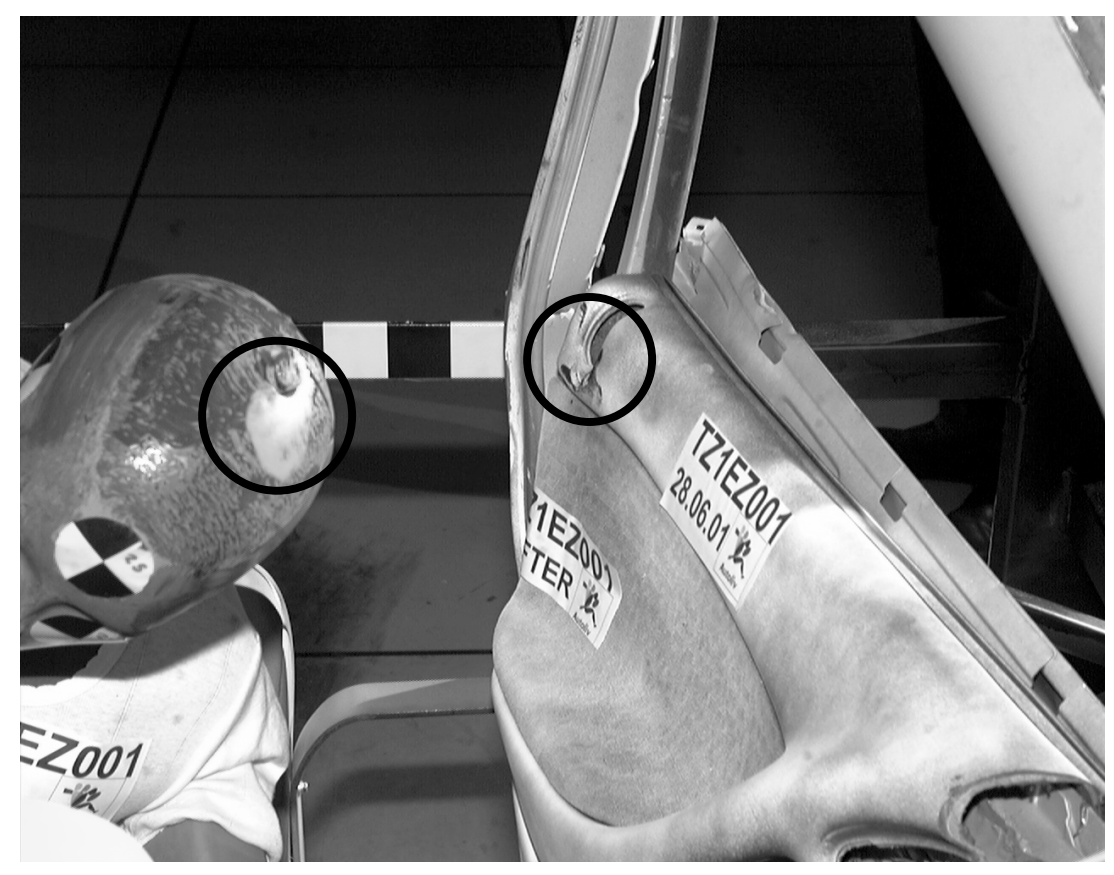

Figure 7 - Post crash photo of the sled test. The contact areas at the dummy head and the door are indicated with circles.

\section{DICUSSION}

The method of chopping and reinforcing a crashed car for use on a sled as described has been shown to be a successful method of replicating a full scale test for the particular set up of dummy, striking and struck vehicle and impact speed. The overlap in time of the events of tunnel deformation and pelvis mid-console interaction was shown to be unnecessary.

The speed of the BioSID-head swipe on the B-pillar/door was less than $7 \mathrm{~km} / \mathrm{h}$. Obviously, a human as 'stiff' as a BioSID would not be injured in a crash condition similar to the one used in this paper. The human ability of lateral flexibility as well as spine straightening and elongation most likely shifts the moderate swipe into a severe impact. According to a simple mathematical analysis there were two opposing effects influencing a potential head impact speed. First, the rotation due to the pelvis-tunnel impact initiating head impact speeds of magnitudes of the vehicle $\Delta \mathrm{v}$. Second, the torque from the lap belt hindered this rotation. Both effects are a function of the lateral flexibility of the occupant. For a crash as assessed in this paper using BioSID, the two effects out-balanced each other with a resulting low head speed. With a human, which is undoubtedly more flexible than a BioSID dummy, the two effects are likely to be minor. Therefore, a preliminary estimate of a human head impact speed in a similar crash to that described in this paper would be of the order of the vehicle change in velocity. In the new FMVSS201 head impact test to provide protection when an occupant's head strikes upper interior components, target points are included for far side crash contacts. The head speed is $24 \mathrm{~km} / \mathrm{h}$ and the resultant HIC(d) should not exceed 1000. Approximately 50\% of far side crashes with belted occupants sustaining MAIS3+ occur at lateral $\Delta \mathrm{v}$ of less than $30 \mathrm{~km} / \mathrm{h}$ according to Digges and Dalmotias [2]. Therefore, the test described in this paper would seem to be an appropriate level of severity for reducing head injury in real-world, far side crashes. 
In order to understand the relationship between crash severity and injury outcome for other striking/struck car mass ratios and impact speeds some explanation is required. In the present side impact test, the struck and the striking car were coupled to each other during the time the dummy would have hit the intruding side. As the change of velocity, $\Delta \mathrm{v}$, for a striking and a struck car was the same after the impact, the law of conservation of momentum gives the following simple $\Delta \mathrm{v}$-formula,

$$
\Delta v=\text { impact speed of the striking car } * \frac{\text { mass of the striking car }}{\text { sum of mass struck and striking car }}
$$

According to this formula, the $\Delta \mathrm{v}$ of the full-scale car was correctly predicted to be $24 \mathrm{~km} / \mathrm{h}$. If the mass ratio would have been 1 instead of 1.7 , as in the present case, the $\Delta v$, and thereby the preliminary estimated human head impact speed, would be in the order of $32 \mathrm{~km} / \mathrm{h}$ (depending to what extent the impact still would be inelastic). For an impact speed of $50 \mathrm{~km} / \mathrm{h}$ (instead of 65 $\mathrm{km} / \mathrm{h}$ ), the $\Delta \mathrm{v}$ would be $18 \mathrm{~km} / \mathrm{h}$.

\section{CONCLUSION}

The first conclusion of this paper is that the cost-effective sled test method developed here was successful in replicating the baseline BioSID full-scale crash. With similar acceleration time histories the dummies in both tests slipped of the sash belt, hit the mid-console, rotated restrained by the lap belt (both in z-direction and angular) and swiped the top of the head against the same spot on the intruded far side of the compartment in virtually identical manner. Also, the test method developed was shown to be practical and useable. According to real-life crash statistics and the magnitude of possible head-to-door/B-pillar collision speeds in other countries, the present $\Delta \mathrm{v}$ does represent a severe injurious event and is practical for most test houses to conduct. Moreover, this test configuration is useful to help develop protection-systems to minimize injury. To summarize, the paper shows that the first step in the following far-side impact research program has been successfully carried out.

Step 1. Establish a cost-effective sled test method

Step 2. Develop a Far Side Dummy

Step 3. Develop countermeasures

Further research is now required to address the remaining two steps in the program.

\section{ACKNOWLEDGEMENTS}

The authors would like to thank the test operation managers Gunther Scheffel and Gareth Brown as well as their staff at the Holden and the Autoliv Australia crash-centre respectively. Thanks are also due to Associate Professor Yngve Haland, Vice President Research of Autoliv Inc. 


\section{REFERENCES}

1. B N Fildes, J C Lane, J Lenard, A P Vulcan, "Passenger cars and occupant injury" Monash University Accident Research Cenre, CR95, March 1991.

2. K Digges and D Dalmotas, "Injuries to restrained occupants in far-side crashes" Proceedings of the $17^{\text {th }}$ ESV Conference, Amsterdam, June 2001.

3. G M Mackay, S Parkin, J Hill, J A R Munns, "Restrained occupants on the non-struck side in lateral collisions" $35^{\text {th }}$ Annual Proccedings Association for the Advancement of Autolotive Medicine, Toronto, Canada, p. 119-131, October 1991.

4. R J Frampton, R Brown, P Thomas, P Fay, "The importance of non struck side occupants in side collisions" $42^{\text {nd }}$ Annual Proccedings Association for the Advancement of Autolotive Medicine”, Charlottesville, Virginia, p. 303-320, October 1998.

5. P Thomas, R Frampton, "Injury patterns in side collisions, a new look with reference to current test methods and injury criteria”, $43^{\text {rd }}$ Stapp Car Crash Conference, San Diego, California, p. 13-24, October 1999.

6. D Otte, E-G Suren, H Appel, J Nehmzov, "Vehicle parts causing injuries to front-seat car passengers in lateral impact" $28^{\text {th }}$ Stapp Car Crash Conference, p. 13-24, October 1984.

7. R Stolinski, R Grzebieta, B Fildes, R Judd, J Wawrzynczak, I Gray, P McGrath, M Case, "Response of far side occupants in car-to-car impacts with standard and modified restraint systems using HIII and US SID", Int. Congress\&Exposition, SAE paper 1999-01-1321, Detroit, USA, March 1999.

8. D Kallieris and G Schmidt, "Neck response and injury assessment using cadavers and the US-SID for far-side lateral impacts of rear seat occupants with inboard-anchored shoulder belts", Proceedings of $34^{\text {th }}$ Stapp Car Crash Conference, Orlando, Florida, p. 93-100, November 1990. 